\title{
Fitness and Musical Taste: Do Physically Fit Listeners Prefer More Stressful Music?
}

\author{
LINDSAY WARRENBURG[1] \\ School of Music, Ohio State University \\ DAVID HURON \\ School of Music, Ohio State University
}

\begin{abstract}
Research suggests that person-based dispositional factors, as well as properties of the music, influence a person's musical taste. In this study, we examined the possibility that the interaction between the stressfulness of the music and a listener's capacity for handling stress contributes to that listener's musical preferences. The key prediction relating fitness to musical preference is that the stressfulness of the music should tend to reflect the person's capacity for handling stress, including his or her physical fitness. The study method made use of an online questionnaire to assess physical fitness, impulsivity and sensation-seeking tendencies, and musical preferences. To create an independent index for estimating musical stressfulness, a parallel study was conducted, where an independent group of judges assessed the stressfulness of the music identified by participants in the main study. The stressfulness of the music was predicted using the survey-based dispositional factors in two regression models, where sex, current age, education, current fitness, and age at the time of musical preference were found to predict the stressfulness of the preferred music. The results suggest that males, younger participants, people with fewer years of education, and those who are more physically fit tend to prefer more stressful music.
\end{abstract}

Submitted 2018 January 13; accepted 2018 October 15.

KEYWORDS: musical preferences, stressfulness, physical fitness, music cognition

DETERMINING the components that influence people's musical tastes has been of interest in industry and academic fields for decades. Starting with Farnsworth's research on musical taste in his seminal work, The Social Psychology of Music (1958), and continuing to the present, it has been shown that many factors influence a person's musical preferences. Two general categories that give rise to a person's musical preferences are properties of the music itself (its acoustical features), and dispositional aspects of the listener. There has been much extant research on listener traits that give rise to musical preferences. Ladinig and Schellenberg (2012) have shown that people who prefer nominally sad music are more likely to exhibit a high Openness score on personality inventories. At the same time, North (2010) found that age and gender influence one's musical taste more than personality traits as measured using the Big Five inventory. Additionally, Geringer and McManus (1979) found that musical preferences correlate with a person's age, musical training, and experience.

The idea that the music itself can be either more or less attractive has a long history. At different times and places, scholars have argued for the importance of formal organization, structural use of harmony, well-designed melody, and appropriate deployment of consonance and dissonance. In the extreme form, it has sometimes been argued that a work of genius represents good music, regardless of whether any listener exhibits a preference for it. In recent decades, the idea that a musical work has inherent properties that make it attractive has been viewed dimly; nevertheless, some empirical studies imply that there may be a biological basis for certain forms of appeal, such as in the case of voice-leading practice (Huron, 2016), or repetitive structures (Huron, 2013).

Despite this previous work in personality research and in music research, no work has related the phenomenon of stress and stress-tolerance to musical preferences. Stress is a subjective phenomenon, and the experience of stress from music listening depends on two general categories. The first refers to 
properties of the music itself - or acoustical factors that are stressful in nature. The second is the dispositional factors of the listener - in the current study, a person's stress tolerance. It is possible that the interaction between the stressfulness of the music and a listener's capacity for handling stress contributes to that listener's musical preferences; it is this idea that motivates the present study.

Factors implicated in music-induced stress include aspects of music composition, such as dissonance, formal organization, lyrics, and harmony; they also include acoustical features for both musical and non-musical sounds. Auditory-induced stressors include, but are not limited to, loudness (Angrilli et al., 1996; Brown et al., 1951; Koch \& Schnitzler, 1997; Parham \& Willott, 1988; Swerdlow et al., 1995), volume or extensity (Stevens \& Davies, 1938), low pitch (Bolinger, 1964; Huron, Kinney \& Precoda, 2006; Morton, 1994; Shanahan \& Huron, 2014), infrasound (Angliss \& O’Keeffe, 2003), scream-like sounds (Beeman, 2005; Sundberg, 1972), acoustic proximity (Ji \& Maren 2007; Mobbs et al., 2007; Sokolov, 1963), and crescendos and diminuendos (Mathews, 1979; Nakamura, 1982, 1987).

People differ in their ability to handle stress. The experience of stress depends on both external situational factors, as well as person-based dispositional traits. Situational factors include physical stressors (such as heat or cold, or threats from conspecifics). Dispositional factors that influence a person's susceptibility to stress include traits such as risk-tolerance and neuroticism; risk-tolerance, in turn, is influenced by traits such as age, gender, and impulsive sensation-seeking. Another prominent factor influencing the level of stress susceptibility is a person's androgen levels. Although androgen levels vary from person to person, males generally have inherently higher levels of certain androgens (notably testosterone) than do females, and this is reflected in the greater risk-tolerance and sensation-seeking behavior evident in male behavior (Campbell et al., 2010). The bifurcation in male/female androgen levels is also echoed in broad differences between male and female general tastes.

Thayer (1997) reviewed and synthesized the extant research literature regarding individual differences in human abilities to handle tension or stress. He noted that the research is consistent with two broad conclusions: (1) that older people are generally less able to handle stress than are younger people, and (2) that the capacity to handle stress is related to physical fitness. Important for the purposes of the current study, Thayer additionally observed that it is possible that the second is the cause of the first: namely, that older people are less able to deal with stress because they are generally less physically fit.

Since musical sounds can evoke different degrees of stress, one might predict that Thayer's summary observation regarding physical fitness could account for some degree of a person's musical preferences. Specifically, one might expect that more physically fit listeners are more likely to prefer music that is deemed more stressful. Two commonly observed music preference trends are consistent with this idea. The first is that older adults, who are generally less physically fit, are known to prefer "milder" music; there is a consistently observed trend that a greater proportion of middle-aged adults begin listening to classical music compared with people of other ages (Foot \& Stoffman, 1996). It is possible that the preference for "milder" music, such as classical music, is due in part to the physical fitness level of the individual. Similarly, it might be that the increased capacity to handle stress explains the second trend, namely that young people, who are more physically fit, are more likely to enjoy Hard Rock, Heavy Metal, Thrash, and other forms of music that might be deemed more tense or stressful. Accordingly, we propose to test Thayer's conjecture with respect to musical preferences.

Existing research has established that the single most important factor influencing preferences is familiarity. Variously characterized as the "Mere Exposure Effect" (Bornstein, 1989), or "Processing Fluency" (Reber, Schwartz \& Winkielman, 2004), the effect of familiarity has been well documented in the case of musical tastes (e.g., Meyer, 1903; Moreland \& Zajonc, 1979; Wilson, 1975, 1979; see Huron, 2006 for a review). This suggests that any purported role of fitness on musical preferences must be understood against a backdrop of familiarity. By way of illustration, consider a physically fit teenager who prefers Heavy Metal, but who experiences a later chronic health problem that results in a permanent decline in physical fitness. Any ensuing change in stress tolerance might be conjectured to influence the acquisition of new musical tastes; however, familiarity with Heavy Metal repertoire is apt to ensure a sustained continued preference for this earlier musical taste. This suggests that an individual's musical preferences may consist of a mixture of genres or styles that are acquired at different phases of life and that the component tastes may echo the fitness levels at each phase. Consequently, in addressing Thayer's conjecture, our main concern should focus on the listener's physical fitness at the time a musical preference is formed.

As noted, a person's physical fitness changes over his or her lifetime, because of year-to-year fluctuations and aging effects. Similarly, one's preferences (both musical and otherwise) change throughout one's lifetime - although tastes appear to be predominantly additive. 
Many researchers have published results about the reminiscence bump, a tendency where adults have increased memories for events that happened when they were between the ages of roughly 12 and 22 (Crovitz \& Schiffman, 1974; Holbrook \& Schindler, 1989; Janssen, Chessa \& Murre, 2007; Schulkind, et al. 1999). This research has been explored by David Rubin (Rubin et al., 2002) and, in terms of music, investigated by Krumhansl and Zupnick (2013). The implications of the reminiscence bump for music are that a person's musical preferences are largely associated with music listened to during the bump period, meaning that musical taste is largely formed during adolescence. Of course, musical tastes can develop at other times in one's life, but the evidence of adolescent preference formation appears robust. In addition to the reminiscence bump, a person's familiarity with songs or works from another point in life can influence musical preferences (Krugman, 1943; North \& Hargreaves, 1995; Russell, 1986, 1987). Relating this to our interest in fitness, a person may have been very fit at the time that he or she formed a musical taste, but may be currently in poor physical fitness; nevertheless, due to familiarity, his or her original taste remains intact, despite the subsequent change in fitness level. New preferences can arise over time, as well. The key prediction relating fitness and musical taste is that at the time the musical preference is formed, the stressfulness of the music will tend to reflect the person's capacity for handling stress, including their physical fitness.

By way of summary, we propose that three personal-dispositional factors may be expected to contribute to the development of a person's musical taste. One is a person's androgen levels (and so their risk-tolerance); a second is the person's listening behavior during the reminiscence bump; and a third is the person's physical fitness at the time the taste is formed. From these considerations, we expect to find a positive correlation between the stressfulness of preferred music and the sensation-seeking dispositions of the listener at the time the preference was formed.

\section{HYPOTHESES}

We expect there to be an interaction between the stressfulness of the preferred music and a listener's capacity for handling stress as reflected in their physical fitness. In formal terms, we may state our hypothesis as follows:

H1. There is a positive association between a listener's physical fitness and the stressfulness of their preferred music.

As noted, many musical tastes are formed principally during adolescence (the period of the reminiscence bump). These musical preferences generally continue throughout a person's lifetime, although further preferences are likely to develop later. If fitness influences preferences, it would be important to note a person's fitness at the time of the preference formation. Accordingly, we might propose the following auxiliary hypothesis:

H2. The stressfulness of a person's preferred music is better correlated with their fitness level at the time the musical preference was formed than with their current fitness level.

\section{METHOD}

For this correlational study, three measures were used: a measure of the physical fitness of individual listeners, a measure of the listeners' preferred music, and a measure of the stressfulness of the identified preferred music. To reach a large and varied sample of participants we elected to make use of an online survey created using the Qualtrics Research Suite. The online questionnaire was used to gauge the physical fitness of individual listeners and to identify their preferred music.

The questionnaire used in this study included a measure of a person's physical fitness habits in different periods of his or her life, a measure of risk-tolerance, and questions intended to characterize participants' musical preferences. We also collected basic demographics, which included age, gender, and education level. Independent of the main questionnaire, we carried out a parallel study where an independent group of participants assessed the stressfulness of the music identified by participants in the main study. This supplementary survey was used to create an independent index for estimating the stressfulness of a given person's musical taste. 


\section{Participants}

Participants were recruited via social media sites, popular online message boards, and by word of mouth. The final sample of individuals $(n=696)$ spanned a wide range of physical fitness levels, impulsivity and sensation seeking scores, education levels, and ages, as detailed in Appendix 3. For the parallel study developed to assess musical stressfulness, participants $(n=28)$ were recruited through Ohio State University and the University of Chicago, and were mainly graduate and undergraduate students in psychology or music. These participants varied in the amount of musical training they had received over their lifetime, ranging from very little or no formal musical training, through music majors at the college level.

\section{Measurement of Physical Fitness}

For the purposes of this study, we needed to assess physical fitness at the time participants formed their musical tastes. There exist many ways of assessing physical fitness. However, most of these methods involve measuring performance on actual physical tasks; these range from elaborate batteries of measures (such as the $\mathrm{VO}_{2}$ Max test), to simpler measures (such as the Harvard Step Test). These cannot be done retrospectively; that is, we cannot ask a participant to perform a physical task as though they were (say) 14 years of age. Fortunately, researchers have developed survey instruments that assess physical fitness through simple questionnaires. One such instrument is the International Physical Activity Questionnaire (IPAQ). The IPAQ is a widely-used instrument for self-reported estimates of physical fitness. An advantage of the IPAQ is that it has been validated in numerous studies against physical fitness measurements such as aerobic and muscular fitness (Craig et al., 2003; Fogelholm et al., 2006; Hagströmer, et al., 2006; Papathanasiou et al., 2010). Unfortunately, the IPAQ estimates a person's fitness by asking questions related to the individual's physical activity during the past seven days. Again, this makes the IPAQ ill-suited to estimating physical fitness some years in the past. Apart from the IPAQ, researchers have used several single-question estimates of fitness. One such example comes from Fogelholm et al. (2006), who asked participants: "Think of the previous three months and consider all leisure time physical activity with duration of at least 20 minutes. How frequently were you physically active?" The use of a single-item survey question has been shown to be an adequate predictor of true physical fitness (Fogelholm et al., 2006; Rütten et al., 2003). Accordingly, our survey asked participants to indicate their current physical fitness using the single-question item validated by Fogelholm et al. (2006). There were concerns that participants may have little recall of the day-to-day physical activities in various times in their lives, but thought they would be better able to recall their physical fitness level relative to their peer group at the time. Consequently, we supplemented the Fogelholm question with an additional comparative question: "Compared to your friends at the time, rate how physically fit you were: (much less fit/slightly less fit/about the same fitness/slightly more fit/much more fit)."

In having participants retrospectively assess their fitness, one consideration was the memory of the participants. We were eager to assist participants in forming vivid reminiscences that would help increase the accuracy of their autobiographical assessments. To this end, we included a series of questions whose sole purpose was to evoke memories of past day-to-day activities. Specifically, we asked if they were attending school at the time, if they recalled their best friends at the time, if they remembered the activities they pursued for fun, and if they remembered how physically active they were at the time. These questions were posed as simple yes or no questions. Given the study's reliance on the participants' recollection of their past, we resolved a priori that we would exclude any participant who answered "no" to any three of the four memory-priming questions. In addition, we excluded any participant who answered "no" to the question: "Do you remember how physically active you were at the time?"

One further problem with the use of questionnaire instruments for assessing fitness was identified by Fogelholm et al. (2006). They discovered that some people misreported their physical fitness on the IPAQ, but also discovered that this misreporting was associated with low levels of education. The researchers concluded that these subjects misunderstood the questions on the IPAQ; when the data for loweducation participants was discarded, the IPAQ was a successful predictor of fitness, correlating well to a person's $\mathrm{VO}_{2}$ Max score. Considering this identified confound, we also asked participants to report their level of educational attainment as part of our survey instrument. 
As noted, if fitness influences preferences, then the fitness of greatest interest is a person's fitness at the time of the preference formation. That is, we anticipate that current fitness level is less predictive of the stressfulness of current musical tastes compared to fitness level at the time the taste was formed. To account for this in our study, when participants stated their favorite artist or piece of music (see below), we further asked them to identify their age when they began to enjoy that music. We then asked a question assessing their physical fitness at the time of preference formation, and asked a second question comparing their physical fitness to their contemporary peer group.

\section{Measurement of Musical Preference}

To characterize musical preferences, we elected to use two methods. The first method employed an openended response, where we simply asked participants to identify their three favorite musicians and/or favorite songs. As mentioned in the above section on physical fitness, they were also asked to estimate the age they were when they started liking the favorite songs they had listed previously. The second method included a list of 21 major musical genres; participants were asked to rank order their top five currently preferred musical genres from this provided list. This genre-list was assembled from allmusic.com, a major commercial source for streamed music; sample items on the list include Avant-Garde, Blues, Classical, Country, etc. Since our focus was on musical preferences, we excluded the allmusic.com category "spoken word/comedy." We also made one additional modification to the Pop/Rock category; this category tends to be a catch-all category that spans highly stressful genres (such as Heavy Metal, Goth, Thrash), and relatively un-stressful genres (such as soft rock, singer-songwriter). Consequently, we divided the Pop/Rock into "Pop/Rock (hard)" and "Pop/Rock (soft)". In addition to the "Pop/Rock (hard)" category, we added two subcategories of Thrash and Goth music. Finally, to the category "children's music" we added the term "Disney." The complete list of categories used is given in Appendix 1. Our hope in using two methods of musical preference was to examine how fitness could predict both current music preferences with the musical genres (which we thought would be more stable over one's lifetime), as well as favorite songs, which are possibly more ephemeral tastes given fads of popular music.

Apart from identifying musical preferences, our hypothesis required a separate assessment of musical stressfulness. For this, we developed an independent index for estimating musical stressfulness, using a separate group of assessors recruited to estimate the stressfulness of the music identified by participants in the main study. Participants were given two tasks: (1) ranking the general stressfulness of the 21 musical genres presented in the main questionnaire, and (2) rating the stressfulness of musical selections identified by individual participants in the main questionnaire on a 7-point Likert scale.

Some song selections were long in duration, so we needed a way to measure stressfulness from a short selection of each song. The raters thus used the first 15 seconds available on the iTunes commercial excerpt for the specified song. In the case of an identified artist or composer, we sampled from the most popular work by that musician as listed on iTunes. The rationale behind this method was that iTunes is likely to use a representative selection of the song. In addition to the musical excerpt itself, assessors therefore also had access to the name of the artist and the name of the song. Given the extent that an artist's name or song title can influence the perceived stressfulness of a work, we deemed it appropriate for the assessors to also have access to this information. The specific instructions given to the participants can be found in Appendix 2.

The complete list of songs identified by participants in the main experiment was divided into smaller sections, so that each listener rated the stressfulness of 95 musical excerpts. From these excerpts, 10 randomly selected songs were rated twice to provide a test-retest measure of reliability, so each rater made 105 judgments. Two different assessors rated each individual excerpt and the ratings were averaged to produce an overall stressfulness score for each selected song.

In addition, each assessor was asked to rank the stressfulness of 21 musical styles from 1 to 21 , where 1 was the most stressful musical genre and 21 was the least stressful musical genre. The instructions for this second task were like those given in Appendix 2, with the exception that no music was heard, and raters were told to do their best by imagining music they suppose might be typical for each of the genres. 


\section{Measurement of Sensation Seeking}

Several instruments have been developed for assessing sensation-seeking. This can be measured through androgen levels and a person's proclivity toward risk-taking behavior. Marvin Zuckerman and colleagues (1964) created a Sensation-Seeking Scale (SSS) that has been widely used across disciplines to measure a person's sensation-seeking tendency. Several versions of Zuckerman's SSS scale have been created, the most recent of which is the Revised SSS-V (Zuckerman, 1996), which employs a 40-item questionnaire. However, for the purposes of this study we made use of the short (19-item) Impulsivity and Sensation Seeking subset of the Zuckerman Kuhlman Personality Questionnaire (2002). This was validated by McDaniel and Mahan III (2008). The 19 test items measure two facets - impulsivity and sensation-seeking - and consist of true or false questions, such as the following: "I like doing things just for the thrill of it," "I would like the kind of life where one is on the move and travelling a lot, with lots of change and excitement," and "I tend to begin a new job without much advance planning on how I will do it."

We realize that impulsivity and sensation-seeking are not stable over the lifetime, and hence the respondent's current impulsivity/sensation-seeking score will differ from their score at the age of their musical preference formation. However, since this measure was 19 questions long, asking it three times (one for each age when the participants started liking their favorite songs) would double the length of the survey and likely increase the rate of attrition. Respondents therefore completed the impulsivity/sensationseeking scale only for their current age. In the statistical analysis, age was assessed independently of sensation seeking, and lifetime variations in age and fitness were considered.

\section{RESULTS}

\section{Stressfulness Assessment}

Before considering the results of the main study, we first need to consider the results of our stressfulness assessment. There were two methods of determining musical stress. The first was a rank order of musical genres, where 1 was the most stressful musical genre and 21 was the least stressful musical genre. The average ranked stress values for the 21 musical styles are shown in Table 1, where a lower score indicates more stressful music, as it was ranked closer to number one in terms of stress. Hard Pop/Rock, Rap, and Avant-Garde, with low "stress-ranks," exhibited the highest stress values, whereas Classical and Easy Listening, with high "stress-ranks," exhibited the lowest stress values. This conforms to previous conceptions of musical stress and suggests that our raters generally agreed with each other and with our expectations of what music is commonly understood as stressful.

The second method of assessing musical stress was to rate the stressfulness of individual songs on a scale of 1-7, where 7 was the most stressful and 1 was the least stressful. Two independent stress ratings were provided for each musical work. We decided a priori to exclude the assessments of any assessors whose judgments correlated poorly with the other assessors, or who showed poor test-retest reliability. Therefore, we excluded data from any assessor whose intra-rater correlation was less than +0.7 , or whose inter-rater correlation was less than +0.5 . In the final sample, the overall intra-rater correlation was 0.92 , meaning that participants strongly agreed with their previous judgments. For the complete set of 1329 songs, the inter-rater correlation was 0.58 . This relatively high positive correlation suggests that the raters broadly agreed in their impressions of musical stressfulness. Accordingly, we averaged the two stress ratings for each work to create a single musical-stress index for each song.

The stressfulness ratings of the songs served as the dependent variable of the main study (see below). Descriptive statistics suggest that participants used the complete range of the scale (from 1-7). The mean stressfulness rating was 3.26 , the median was 3.0 , and the standard deviation was 1.46 . Although the stressfulness ratings fail the Kolmogorov-Smirnov test of normality (test statistic $=0.124, p<.01$ ), a standard histogram and a Q-Q plot of the data indicate that the data are reasonably normal in distribution. 
Table 1. Normalized average ranked stress of 21 musical genres, where lower numbers indicate more stressful genres.

\begin{tabular}{ll}
\hline Musical Stress & Mean Stress-Rank Value \\
\hline Hard Pop/Rock & 5.83 \\
Rap & 7.02 \\
Avant-Garde & 7.46 \\
Electronic & 7.60 \\
Soft Pop/Rock & 9.86 \\
Latin & 10.06 \\
International & 10.57 \\
Stage and Screen & 11.00 \\
Jazz & 11.31 \\
Blues & 11.42 \\
Religious & 11.46 \\
Country & 11.80 \\
New Age & 11.83 \\
R\&B & 11.97 \\
Reggae & 12.14 \\
Children & 12.57 \\
Holiday & 12.60 \\
Vocal & 12.77 \\
Folk & 13.06 \\
Classical & 13.77 \\
Easy Listening & 14.89 \\
\hline
\end{tabular}

\section{Main Study}

For the main study, we surveyed 696 participants via an online questionnaire ( $48 \%$ male). In recruiting participants online, we aimed to recruit a wide range of degrees of physical fitness and ages to increase the likelihood of obtaining a high degree of statistical power. Participants spanned ages 18-65, but the sample was biased towards younger participants $(M=32.68$ years old, $S D=11.65)$. Participants spanned the entire Impulsivity-Sensation Seeking scale, as well as the entire range of fitness scores. A summary of participant demographics is shown in Appendix 3.

Before testing our main hypotheses, it was appropriate to consider various criteria for including or excluding data. We identified a priori conditions for inclusion. Respondent data would be included only if there was evidence that he or she exhibited reasonable recollection of their life at the time the taste was formed. To this end, a set of "yes or no" questions were included in the main questionnaire. These questions served two purposes: to help prime respondents' memory and to assess the vividness of their past recollection. The pertinent queries included questions about the time the musical preference was formed, such as whether they were in school, what they did for fun, who their best friends were, and how physically active they were. Participants were excluded if they could not recall how physically active they were at this time in their life or if they could not answer three or more of the memory-priming questions.

An obvious confound in addressing the hypothesis is the effect of age. In the first instance, one expects that physical fitness will tend to decline with age. At the same time, there are clear differences in musical taste that are related to an age cohort. For example, historically, music appears to have become more dissonant over time. If we find that older listeners are less fit and that older listeners also prefer less dissonant music, this correlation might be an artifact of a third variable, namely age-related musical popularity, rather than fitness level. To circumvent this, one might focus on comparisons of physical fitness within age groups. Accordingly, we aimed for a stratification of ages in our analyses; that is, age should be present as a covariate in any statistical test.

The main hypothesis was that there is a positive association between a listener's physical fitness at the time of musical preference formation and the stressfulness of the preferred music. The corollary hypothesis was that the stressfulness of a person's preferred music is better correlated with their fitness level at the time the musical preference was formed than with their current fitness level. We tested these 
hypotheses using two linear models, one aimed at the stressfulness of a person's preferred musical songs (where the preference could have been formed at any point in the lifespan) and one at the stressfulness of a person's currently preferred musical genres. All statistical tests were conducted using IBM SPSS-Statistics and JMP.

The first method made use of a linear regression model, where the dependent variable was the average stressfulness ratings of the songs picked by each person from the main study (see Table 2). The first step of the regression used five independent variables to predict the stressfulness ratings: (1) the participant's current fitness level, (2) the current reported age of the respondent, (3) the impulsivity/sensation-seeking scores, (4) the respondent's sex, and (5) the participant's educational attainment. The $\mathrm{R}^{2}$ from these variables was .034. The second step of the regression added two predictors of interest in a set-wise fashion: (1) a person's fitness at the time of musical preference formation and (2) a person's age at the time of musical preference formation. Together, these two predictors explained an additional $1.5 \%$ of the variability in the stressfulness ratings of the songs. Fitness at the time of musical preference formation, our main predictor of interest, had a squared semi-partial correlation of only .0012 and was not found to be significant. Overall, we found that all predictors except fitness at the time of musical preference formation and impulsivity/sensation-seeking were significant. Our analysis showed that males, younger participants, people with fewer years of education, and those who are more physically fit tend to prefer more stressful music. Interestingly, the older people were when they started liking a song, the more stressful the music tended to be. Most likely this is an artifact of the ages when people formed their musical preferences, some of which were around the ages of 3-10, when people are unlikely to prefer stressful music. However, even for the predictors that were significant, the regression weights and $\mathrm{R}^{2}$ were very small. This means that although many of the findings were in the direction we expected, with the notable exception of the fitness at the time of musical preference formation, there are other factors that must be considered.

Table 2. Linear Regression predicting the stressfulness ratings of musical songs in two steps. The first step considered a person's sex, current age, education, current fitness, and impulsivity/sensation-seeking scores. The second step treated these five variables as covariates and examined the variability explained by the two predictors of interest: age and fitness, both at the time of musical preference formation.

\begin{tabular}{lcc}
\hline Predictor & $\boldsymbol{b}$ & $\boldsymbol{p}$ \\
\hline Sex & -.203 & .021 \\
Current Age & -.025 & $<.001$ \\
Education & -.098 & .019 \\
Current Fitness & .064 & .044 \\
Impulsivity/Sensation-Seeking & -.002 & .841 \\
Age at the time of musical preference & .021 & $<.001$ \\
Fitness at the time of musical preference & .035 & .209 \\
\hline
\end{tabular}

The second method used a linear regression model to predict the stressfulness of a person's currently preferred musical genres. The goal was to examine whether age moderated the relationship between physical fitness and the stressfulness of the musical preferences. The stressfulness of currently preferred musical genres was used as the dependent variable, as the genres provided a current indication of people's overall musical tastes. The relationship between currently preferred music and current age/fitness is likely to be stronger than the relationship between music at different points in one's life and the corresponding age/fitness at that time. Therefore, the focal predictor was the person's current fitness level, with current age acting as the moderator. Once again, we statistically controlled for a person's score on impulsivity/sensation-seeking, sex, and educational attainment. Like the first regression model, the $\mathrm{R}^{2}$ of the model was very small, meaning our predictors did not explain much variability in the stressfulness values (see Table 3). Impulsivity/sensation-seeking and education did not explain any variability in the stressfulness values of the music. Current age and fitness were each significant, consistent with our hypothesis that younger people and people who are more fit prefer more stressful musical genres. However, the moderation between age and fitness level was not significant $(p=.141)$. Sex was significant and was weighted stronger than any other predictor. Again, we can see that males prefer more stressful music than do females, consistent with the hypothesis that androgen levels may play a role in preference formation. 
Table 3. Linear Regression examining if current age moderated the relationship between current physical fitness and currently preferred musical genres, controlling for sex, education, and impulsivity/sensationseeking scores.

\begin{tabular}{lcc}
\hline Predictor & $\boldsymbol{b}$ & $\boldsymbol{p}$ \\
\hline Sex & -.838 & $<.001$ \\
Impulsivity/Sensation-Seeking & .030 & .068 \\
Education & .097 & .135 \\
Current Fitness & .177 & $<.001$ \\
Current Age & -.042 & $<.001$ \\
Moderation (cross-product of fitness and age) & .005 & .141 \\
\hline
\end{tabular}

Although the interaction between fitness and age was not significant, a post hoc regression indicated that impulsivity/sensation-seeking and fitness at the time of musical preference formation do interact $(F=3.15$, $p=.043$ ), although neither of the main effects were significant. To perform this regression, a median split was conducted, where people in the bottom $50 \%$ of fitness were assigned to "low fitness" and people in the top $50 \%$ of fitness were assigned to "high fitness." Similarly, impulsivity scores were divided into low (bottom 25\%), medium (middle 50\%), and high (top 25\%) categories. Using this new metric, it was found that people who are high in impulsivity and in fitness preferred more stressful music than did people high in impulsivity and low in fitness. This suggests that fitness moderates the relationship between impulsivity and stressfulness (see Figure 1).

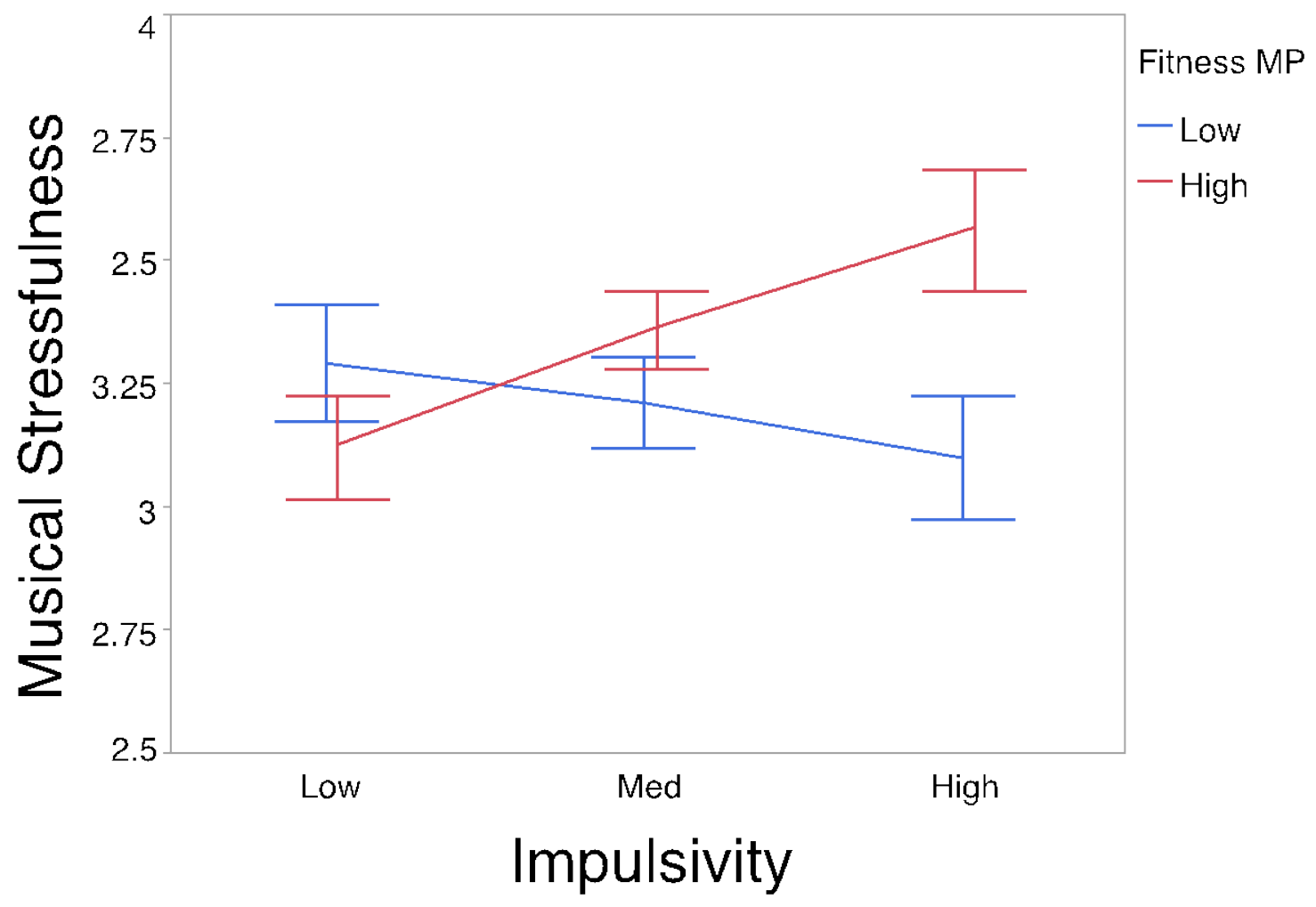

Fig. 1. Interactions between impulsivity and fitness. Among people with low and medium impulsivity ratings, the stressfulness ratings of preferred music do not differ between those low in fitness and high in fitness. Among people with high impulsivity ratings, the stressfulness ratings of preferred music are significantly different between those with low and high fitness levels: people with higher fitness preferred more stressful music than people with lower fitness. The error bars represent standard error values. 
Because the explained variability in the music stressfulness values was low, we conducted one additional post hoc test. Presumably, people will have similar preferences in overall musical genres and in individual songs. We were interested in whether the stressfulness of the preferred songs could help predict the stressfulness of the preferred genres, which would be the case if people tend to prefer songs that are similar in stress to their overall preferred genres. Another multiple linear regression was conducted, where the dependent variable was the stressfulness of the musical genres. The predictors were impulsivity/sensationseeking scores, education, gender, current fitness, and the stressfulness of the person's preferred songs. The more stressful each individual song a person preferred was, the more stressful the preferred musical genres were $(b=.416, t=-9.578, p<.001)$. The squared semi-partial correlation of preferred songs was .067 ; this means only about $7 \%$ of the variance in the stressfulness of preferred musical genres was explained by the stressfulness of the preferred songs. With the stressfulness of the preferred songs in the model, the total $\mathrm{R}^{2}$ was .156, meaning that only $15 \%$ of the variance of the stressfulness in preferred musical genres can be accounted for, even with this new predictor added. The correlation between the stressfulness of songs and stressfulness of the genres was found to be only .296, an unexpected finding that shows how variable people's musical tastes can be.

\section{DISCUSSION}

Research today is becoming aligned with interactionist theories, especially in terms of lifestyle preferences (Bonneville-Roussy et al., 2013; Greenberg et al., 2015; Swann, Rentfrow, \& Guinn, 2002). These theories suggest that people's dispositional characteristics influence the types of activities, environments, and stimuli to which they are attracted. In the current study, we predicted that people who are higher in physical fitness and so more stress tolerant would prefer music that is also more stressful in nature. Although the mechanism by which this association might arise has not been addressed, one might speculate that a preference for high arousal music by high-fitness listeners could be attributed to changes of perception, where highly energetic music is simply perceived as less stressful. That is, for more physically fit listeners, acoustical factors associated with stress (such as high intensity, high extensity, low pitch, scream-like timbres, acoustic proximity, and crescendos) may be perceived as less stressful. Consequently, those who exhibit higher physical fitness may be more likely to prefer high arousal music such as Death Metal, Thrash, Hard Rock, or Screamo. Of further potential interest is the role of personality. It is known that people who prefer energetic rap and dance music are more likely to exhibit trait extraversion (McCown et al., 1997); moreover, arousal and pleasure are positivity correlated for extraverts (Kuppens, 2008).

In terms of our two hypotheses, the first was that there is a positive association between a listener's physical fitness at the time of musical preference formation and the stressfulness of the preferred music. It appears that the results are consistent with this hypothesis. The current fitness level did predict some of the variability in the stressfulness of the preferred music; however, the variability it does explain is small. The second hypothesis was that the stressfulness of a person's preferred music is better correlated with their fitness level at the time the musical preference was formed than with their current fitness level. The results were not consistent with this claim: fitness at the time of musical preference formation did not account for any variability in the stressfulness of the preferred music.

Although the results of the study are in the direction we predicted, the variability in people's musical preferences accounted for by their fitness, stress-tolerance, and age is low. There are many more factors that play into a person's musical preferences that cannot be accounted for by a simple linear model. Additionally, the effects of our predictors may not be linear. As an example of the complex relationship between dispositional factors and preference for musical stressfulness, consider the following facts about the survey participants. People who preferred music rated as the most stressful spanned the entire scale for both current fitness and fitness at the time of the music preference formation. They also spanned almost the entire scale of impulsivity/sensation seeking scores. Finally, the age span of when they started liking their preferred music was from 15-30. People who preferred music rated as the least stressful spanned the entire scale for current fitness and fitness at the time of music preference formation, spanned the entire scale for impulsivity/sensation-seeking scores, and the age when they started liking their favorite music spanned the ages of 10-60. Therefore, the data variability among people who like different musical tastes is vast. In a post hoc examination, it was found that there is an almost 0 correlation between impulsivity/sensationseeking scores and a person's fitness level $(r=.035)$.

The results are consistent with the idea that males, younger people, and those with higher current fitness levels prefer more stressful music. This is in line with recent research that suggests older adults 
prefer reflective and complex music, while younger adults prefer intense and rebellious music (Clark \& Giacomantonio, 2015). In contrast to a previous study that suggests that people who score higher in impulsivity/sensation-seeking prefer music that is more stimulating (Litle \& Zuckerman, 1986), we found no relationship between impulsivity/sensation-seeking scores and a preference for stressful music. Additionally, it appears that the younger people are when they start liking a musical song, the less stressful that preferred song tends to be. This makes sense, as people started liking preferred songs at the age of 3 . It seems highly unlikely that children would like stressful songs, no matter their sex or fitness level.

In a similar line of reasoning, a person's fitness when they are young does not tell us much about their proclivity toward "stressful" stimuli and activities, such as music listening. For example, many people reach normal fitness levels when they are 10 years old. Also, knowing the fitness level is likely less predictive of personality and stress-tolerance in youth than it is in adulthood. Therefore, it doesn't mean that Thayer's (1997) conjecture is invalid, but certainly means that it is confounded by additional factors. Also, people's reported fitness level did not change very much from their current age and reported age at the time of musical preference formation. In fact, in 461 of 1165 trials (39.57\% of the time), people reported the same fitness level for current fitness and fitness at the time of musical preference formation. The statistical tolerance for the two fitness levels was moderately low, meaning that both fitness levels explain the same variability (tolerance for current fitness $=.573$, tolerance for fitness at the time of musical preference $=.813$ ). Although it is possible that people's physical fitness did not change across the two periods of time, it is also possible that the retrospective rating of past fitness through an individual's memory does not provide an accurate rating. Instead, people's assessment of past fitness could be tied to their current fitness, regardless of the true value of their past fitness level.

In terms of musical stressfulness, participants generally agreed that fifteen seconds was long enough to rate the stressfulness of the music excerpts. Common acoustical and musical factors that participants used to determine the stress of a musical selection were timbre or instrumentation, tempo, tonality, acoustic distortion, vocal quality (such as screaming), and repetition/predictability. Many participants also emphasized that they made their judgments based on how the music made them feel when listening. One of the ways that the two seemingly disparate forms of stress could be related is that musical preferences mirror the person's mindset. For example, when a person is stressed, they tend to listen to more stressful music. Additionally, the music that a person finds to be stressful could depend on the stress level in his or her daily life, as well as the familiarity with a musical work. A common response of participants was that music and emotional stress can influence each other, but do not totally overlap. Some people thought that the music they listen to has an influence on events in their day, including emotions experienced and stress levels. Others thought that the emotional state or stress level of the person affects the type of music he or she would want to listen to (especially emotionally congruent music). Despite a possible relationship between musical and daily stress, the two forms of stress do differ in two important ways. Firstly, the time frame of experienced stress differs, where music is more temporary than daily stress. Secondly, musical stress is not "real," whereas daily stress permeates across aspects of life, such as health and personal relationships. The fact that participants believed there to be a relationship between the two forms of stress is interesting; this potential relationship should be pursued in future research.

A relationship between musical and daily stress could be related to Thayer's original hypothesis, which motivated this study: that older people are less able to deal with stress because they are generally less physically fit. Although this hypothesis discusses stress in terms of a person's daily life, we wondered if this hypothesis could be used to explain why older adults, who are generally less physically fit, come to prefer "milder" music. Similarly, we questioned whether more physically fit listeners were more likely to prefer music that is deemed as more stressful. Although our results are consistent with this hypothesis, the low variability explained by the predictors of interest suggest that there are many more factors that play into a person's given musical tastes than we can account for with our study. Future research should address such additional factors. In conclusion, we have contributed some evidence to interactionist theories, where dispositional and physical factors are thought to affect lifestyle preferences, such as musical taste.

\section{ACKNOWLEDGMENTS}

This article was copyedited by Scott Bannister and layout edited by Kelly Jakubowski. 


\section{NOTES}

[1] Correspondence can be addressed to: Lindsay Warrenburg, Ohio State University, 1871 N. High St., Columbus, OH, 43210, warrenburg.3@osu.edu.

\section{REFERENCES}

Angliss S., \& O'Keeffe, C. (2003). Soundless Music: Concert-based experimentation with Infrasound. Unpublished manuscript.

Angrilli, A., Mauri, A., Palomba, D., Flor, H., Birbaumer, N., Sartori, G., \& di Paola, F. (1996). Startle reflex and emotion modulation impairment after a right amygdala lesion. Brain, 119(6), 1991-2000. https://doi.org/10.1093/brain/119.6.1991

Beeman, W. O. (2005). Making grown men weep. Aesthetics in Performance: Formations of Symbolic Construction and Experience, 24-42.

Bolinger, D.L. (1964). Intonation across languages. In: J.H. Greenberg, C.A. Ferguson \& E.A. Moravcsik (Eds.), Universals of Human Language, Vol. 2: Phonology. Stanford, CA: Stanford University Press, pp. 471-524.

Bonneville-Roussy, A., Rentfrow, P. J., Xu, M. K., \& Potter, J. (2013). Music through the ages: Trends in musical engagement and preferences from adolescence through middle adulthood. Journal of Personality and Social Psychology, 105(4), 703-713. https://doi.org/10.1037/a0033770

Bornstein, R. F. (1989). Exposure and affect: Overview and meta-analysis of research, 1968-1987. Psychological Bulletin, 106(2): 265-289. https://doi.org/10.1037/0033-2909.106.2.265

Brown, J. S., Kalish, H. I., \& Farber, I. E. (1951). Conditioned fear as revealed by magnitude of startle response to an auditory stimulus. Journal of Experimental Psychology, 41(5), 317-328. https://doi.org/10.1037/h0060166

Campbell, B. C., Dreber, A., Apicella, C. L., Eisenberg, D. T., Gray, P. B., Little, A. C., ... \& Lum, J. K. (2010). Testosterone exposure, dopaminergic reward, and sensation-seeking in young men. Physiology \& Behavior, 99(4), 451-456. https://doi.org/10.1016/j.physbeh.2009.12.011

Clark, S. S., \& Giacomantonio, S. G. (2015). Toward Predicting Prosocial Behavior: Music Preference and Empathy Differences Between Late Adolescents and Adults. Empirical Musicology Review, 10(1). https://doi.org/10.18061/emr.v10i1-2.4602

Craig, C. L., Marshall, A. L., Sjöström M., Bauman, A. E., Booth, M. L., Ainsworth, B. E., et al. (2003). International Physical Activity Questionnaire: 12-country reliability and validity. Medicine \& Science in Sports \& Exercise, 35, 1381-1395. https://doi.org/10.1249/01.MSS.0000078924.61453.FB

Crovitz, H. F., \& Schiffman, H. (1974). Frequency of episodic memories as a function of their age. Bulletin of the Psychonomic Society, 4(5), 517-518. https://doi.org/10.3758/BF03334277

Farnsworth, P. R. (1958). The social psychology of music. Ames, IA: Iowa State University Press.

Fogelholm, M., Malmberg, J., Suni, J., Santtila, M., Kyröläinen, H., Mäntysaari, M., \& Oja, P. (2006). International physical activity questionnaire: validity against fitness. Medicine and Science in Sports and Exercise, 38(4), 753-760. https://doi.org/10.1249/01.mss.0000194075.16960.20

Foot, D. K., \& Stoffman, D. (1996). Boom bust and echo: how to profit from the coming demographic shift. Toronto: Macfarlane Walter \& Ross. 
Geringer, J. M., \& McManus, D. (1979). A survey of musical taste in relationship to age and musical training. In College Music Symposium (pp. 69-76). The College Music Society.

Greenberg, D. M., Rentfrow, P. J., \& Baron Cohen, S. (2015). Can Music Increase Empathy? Interpreting Musical Experience Through the Empathizing-Systemizing (ES) Theory: Implications For Autism. Empirical Musicology Review, 10(1), 79-94. https://doi.org/10.18061/emr.v10i1-2.4603

Hagströmer, M., Oja, P., \& Sjöström, M. (2006). The International Physical Activity Questionnaire (IPAQ): A study of concurrent and construct validity. Public Health Nutrition, 9(6), 755-762. https://doi.org/10.1079/PHN2005898

Holbrook, M. B., \& Schindler, R. M. (1989). Some exploratory findings on the development of musical tastes. Journal of Consumer Research, 16(1), 119-124. https://doi.org/10.1086/209200

Huron, D. (2013). A psychological approach to musical form: The habituation-fluency theory of repetition. Current Musicology, 96, 7-35. https://doi.org/10.7916/D8KP81FG

Huron, D. (2016). Voice Leading: The Science Behind a Musical Art. Cambridge, Massachusetts: MIT Press. https://doi.org/10.7551/mitpress/9780262034852.001.0001

Huron, D., Kinney, D., \& Precoda, K. (2006). Influence of pitch height on the perception of submissiveness and threat in musical passages. Empirical Musicology Review, 1(3), 170-177. https://doi.org/10.18061/1811/24068

Janssen, S. M., Chessa, A. G., \& Murre, J. M. (2007). Temporal distribution of favourite books, movies, and records: Differential encoding and re-sampling. Memory, 15(7), 755-767. https://doi.org/10.1080/09658210701539646

Ji, J., \& Maren, S. (2007). Hippocampal involvement in contextual modulation of fear extinction. Hippocampus, 17(9), 749-758. https://doi.org/10.1002/hipo.20331

Koch, M., \& Schnitzler, H. U. (1997). The acoustic startle response in rats - circuits mediating evocation, inhibition and potentiation. Behavioural Brain Research, 89(1), 35-49. https://doi.org/10.1016/S01664328(97)02296-1

Krugman, H. E. (1943). Affective response to music as a function of familiarity. The Journal of Abnormal and Social Psychology, 38(3), 388-392. https://doi.org/10.1037/h0061528

Krumhansl, C. L., \& Zupnick, J. A. (2013). Cascading reminiscence bumps in popular music. Psychological Science, 24(10), 2057-2068. https://doi.org/10.1177/0956797613486486

Kuppens, Peter (2008). Individual differences in the relationship between pleasure and arousal. Journal of Research in Personality, 42(4): 1053-9. https://doi.org/10.1016/j.jrp.2007.10.007

Ladinig, O., \& Schellenberg, E. G. (2012). Liking unfamiliar music: Effects of felt emotion and individual differences. Psychology of Aesthetics, Creativity, and the Arts, 6(2), 146-154. https://doi.org/10.1037/a0024671

Litle, P., \& Zuckerman, M. (1986). Sensation seeking and music preferences. Personality and Individual Differences, 7(4), 575-578. https://doi.org/10.1016/0191-8869(86)90136-4

Mathews, M. V. (1979). Perception of crescendos as a function of duration. The Journal of the Acoustical Society of America, 65(S1), S123-S123. https://doi.org/10.1121/1.2017011 
McCown, W., Keiser, R., Mulhearn, S., \& Williamson, D. (1997). The role of personality and gender in preference for exaggerated bass in music. Personality and Individual Differences, 23(4), 543-547. https://doi.org/10.1016/S0191-8869(97)00085-8

McDaniel, S. R., \& Mahan, J. E. (2008). An examination of the ImpSS scale as a valid and reliable alternative to the SSS-V in optimum stimulation level research. Personality and Individual Differences, 44(7), 1528-1538. https://doi.org/10.1016/j.paid.2008.01.009

Meyer, M. (1903). Experimental studies in the psychology of music. American Journal of Psychology, 14, 456-475. https://doi.org/10.2307/1412315

Mobbs, D., Petrovic, P., Marchant, J. L., Hassabis, D., Weiskopf, N., Seymour, B., ... \& Frith, C. D. (2007). When fear is near: Threat imminence elicits prefrontal-periaqueductal gray shifts in humans. Science, 317(5841), 1079-1083. https://doi.org/10.1126/science.1144298

Moreland, R. L., \& Zajonc, R. B. (1979). Exposure effects may not depend on stimulus recognition. Journal of Personality and Social Psychology, 37, 1085-1089. https://doi.org/10.1037/00223514.37.6.1085

Morton, E. S. (1994). Sound symbolism and its role in non-human vertebrate communication. In L. Hinton, J. Nichols, and J. J. Ohala (Eds.), Sound symbolism (pp. 348-365) Cambridge, UK: Cambridge University Press. https://doi.org/10.1017/CBO9780511751806.023

Nakamura, T. (1982). The effect of pitch pattern on the recognized crescendo and decrescendo. In Reports of the 1982 Spring Meeting of the Acoustical Society of Japan (pp. 215-216).

Nakamura, T. (1987). The communication of dynamics between musicians and listeners through musical performance. Perception \& Psychophysics, 41(6), 525-533. https://doi.org/10.3758/BF03210487

North, A. (2010). Individual differences in musical taste. American Journal of Psychology, 123(2), 199208. https://doi.org/10.5406/amerjpsyc.123.2.0199

North, A. C., \& Hargreaves, D. J. (1995). Subjective complexity, familiarity, and liking for popular music. Psychomusicology: A Journal of Research in Music Cognition, 14(1-2), 77-93. https://doi.org/10.1037/h0094090

Papathanasiou, G., Georgoudis, G., Georgakopoulos, D., Katsouras, C., Kalfakakou, V., \& Evangelou, A. (2010). Criterion-related validity of the short International Physical Activity Questionnaire against exercise capacity in young adults. European Journal of Cardiovascular Prevention \& Rehabilitation, 17(4), 380386. https://doi.org/10.1097/HJR.0b013e328333ede6

Parham, K., \& Willott, J.F. (1988). Acoustic startle response in young and aging C57BL/6J and CBA/J mice. Behavioral Neuroscience, 102(6), 881-886. https://doi.org/10.1037/0735-7044.102.6.881

Reber, R., Schwarz, N., \& Winkielman, P. (2004). Processing fluency and aesthetic pleasure: Is beauty in the perceiver's processing experience? Personality and Social Psychology Review, 8(4), 364-382. https://doi.org/10.1207/s15327957pspr0804_3

Russell, P. A. (1986). Experimental aesthetics of popular music recordings: Pleasingness, familiarity and chart performance. Psychology of Music, 14(1), 33-43. https://doi.org/10.1177/0305735686141003

Russell, P. A. (1987). Effects of repetition on the familiarity and likeability of popular music recordings. Psychology of Music, 15(2), 187-197. https://doi.org/10.1177/0305735687152006

Rütten, A., Vuillemin, A., Ooijendijk, W. T. M., Schena, F., Sjöström, M., Stahl, T., ... \& Ziemainz, H. (2003). Physical activity monitoring in Europe. The European Physical Activity Surveillance System 
(EUPASS) approach and indicator testing. Public Health Nutrition, 6(4), 377-384. https://doi.org/10.1079/PHN2002449

Schulkind, M. D., Hennis, L. K., \& Rubin, D. C. (1999). Music, emotion, and autobiographical memory: They're playing your song. Memory \& Cognition, 27(6), 948-955. https://doi.org/10.3758/BF03201225

Shanahan, D., \& Huron, D. (2014). Heroes and villains: the relationship between pitch tessitura and sociability of operatic characters. Empirical Musicology Review, 9, 46-59. https://doi.org/10.18061/emr.v9i2.4441

Sokolov, E. N. (1963). Perception and the conditioned reflex. New York: McMillan.

Stevens, S. S., \& Davies, H. (1983). Hearing: Its psychology and physiology. American Institute of Physics for the Acoustical Society of America.

Sundberg, J. (1974). Articulatory interpretation of the "singing formant". The Journal of the Acoustical Society of America, 55(4), 838-844. https://doi.org/10.1121/1.1914609

Swann, W. B. Jr., Rentfrow, P. J., \& Guinn, J. S. (2002). Self-verification: The search for coherence. In M. Leary \& J. Tagney (Eds.), Handbook of Self and Identity (pp. 367-383). New York: Guilford Press.

Swerdlow, N. R., Paulsen, J., Braff, D. L., Butters, N., Geyer, M. A., \& Swenson, M. R. (1995). Impaired prepulse inhibition of acoustic and tactile startle response in patients with Huntington's disease. Journal of Neurology, Neurosurgery \& Psychiatry, 58(2), 192-200. https://doi.org/10.1136/jnnp.58.2.192

Thayer, R.E. (1997). The origin of everyday moods: Managing energy tension, and stress. Oxford University Press.

Wilson, W. R. (1975). Unobtrusive induction of positive attitudes. Ph.D. dissertation, University of Michigan.

Wilson, W. R. (1979). Feeling more than we can know: Exposure effects without learning. Journal of Personality and Social Psychology, 37, 811-821. https://doi.org/10.1037/0022-3514.37.6.811

Zuckerman, M., Kolin, E. A., Price, L., \& Zoob, I. (1964). Development of a sensation-seeking scale. Journal of Consulting Clinical Psychology, 32, 420-426. https://doi.org/10.1037/h0040995

Zuckerman, M. (1996). Item revisions in the sensation seeking scale form V (SSS-V). Personality and Individual Differences, 20(4), 515. https://doi.org/10.1016/0191-8869(95)00195-6

Zuckerman, M. (2002). Zuckerman-Kuhlman personality questionnaire (ZKPQ): An alternative fivefactorial model. In B. de Raad \& M. Perugini (Eds.), Big five assessment (pp. 376-392). Ashland, OH: Hogrefe \& Huber. 


\section{APPENDIX 1: List of Musical Genres Used to Assess Musical Preferences}

\section{Musical Genres}

Avant-Garde (modern composition)

Blues

Children's Music/Disney

Classical (ballet, band music, chamber music, choral, opera, orchestral, symphony)

Country

Easy Listening

Electronic (house, techno, trance)

Folk

Holiday

International (non-western traditional, worldbeat)

Jazz (big band/swing, bop, contemporary jazz, cool, free jazz, Latin jazz/world fusion, New Orlean/classic jazz)

Latin

New Age

Soft Pop/Rock (alternative/indie rock, art-rock/experimental, dance, europop, psychedelic/garage, singer/songwriter) Hard Pop/Rock (goth, hard rock, heavy metal, punk/new wave, thrash)

$\mathrm{R} \& \mathrm{~B}$ (soul)

Rap

Reggae

Religious

Stage \& Screen (cast recordings, film music, television music)

Vocal (acappella, barbershop quartet, cabaret, composer songbook, Tin Pan Alley pop, vaudeville) 


\section{APPENDIX 2: Participant Instructions}

Assessors received the following instructions:

In this experiment, you will hear a series of musical excerpts. For each excerpt, please rate on this scale how "stressful" you think most people would regard this music. By stressful, you might consider such factors as the tempo of the music, the loudness, the amount of dissonance, the timbres employed, the content of lyrics, the predictability of the music, etc.

Please do your best to avoid letting your personal preferences influence your ratings. That is, please don't rate an excerpt more stressful simply because you don't like it or you are not familiar with it. Remember, we would like you to respond according to how stressful you think most people would find the music, rather than according to your own personal taste. In addition, please try to respond using the full 7-point scale. Do you have any questions? 


\section{APPENDIX 3: Participant Demographics}

\begin{tabular}{|c|c|c|}
\hline Demographic & $\begin{array}{l}\text { Range (Average, Standard } \\
\text { Deviation) }\end{array}$ & Possible range of answers \\
\hline Gender & $48 \%$ male, $52 \%$ female & \\
\hline Current Age & $18-65(\mathrm{M}=32.7, S D=11.65)$ & \\
\hline Current Fitness Level & $1-6(M=3.65, S D=1.7)$ & $\begin{array}{l}1-6, \text { where } 1=\text { least physically fit, } \\
6=\text { most physically fit }\end{array}$ \\
\hline $\begin{array}{l}\text { Current Fitness Compared to } \\
\text { Friends Fitness }\end{array}$ & $1-6(M=3.04, S D=1.12)$ & $\begin{array}{l}1-5, \text { where } 1=\text { much less } \\
\text { physically fit than friends, } 5= \\
\text { much more physically fit than } \\
\text { friends }\end{array}$ \\
\hline $\begin{array}{l}\text { Age at Musical Preference } \\
\text { Formation }\end{array}$ & $3-63(M=22.4, S D=9.5)$ & \\
\hline $\begin{array}{l}\text { Fitness at Musical Preference } \\
\text { Formation }\end{array}$ & $1-6(M=3.78, S D=1.66)$ & $\begin{array}{l}1-6 \text {, where } 1=\text { least physically fit, } \\
6=\text { most physically fit }\end{array}$ \\
\hline Education & $\begin{array}{l}4-10(M=9 ; \text { currently in grad } \\
\text { school })\end{array}$ & $\begin{array}{l}1-10, \text { where } 1=\mathrm{K}-4^{\text {th }} \text { grade, } 4= \\
\text { sophomore in HS, } 8=\text { completed } \\
\text { a Bachelor's degree, } 10= \\
\text { completed a professional/ } \\
\text { graduate degree }\end{array}$ \\
\hline Impulsivity-Sensation Seeking & $0-18(M=7.07, S D=4.13)$ & $\begin{array}{l}0-18 \text {, where } 0 \text { is the lowest score } \\
\text { possible (least impulsive) and } 18 \\
\text { is the highest score possible } \\
\text { (most impulsive) }\end{array}$ \\
\hline
\end{tabular}

